\title{
Research on Computer Network Security Assessment Based on Fuzzy Analytic Hierarchy Process
}

\author{
Chun-yuan Li \\ Department of Mathematics, Baicheng Normal University, Baicheng, China \\ lichunyuan521@126.com
}

Keywords: Computer network; Network security; Assessment; Fuzzy analytic hierarchy process; Triangular fuzzy number

Abstract. The hierarchy model of computer network security assessment was constructed in light of the characteristics of computer network and the factors influencing the network security. The fuzzy analytic hierarchy process based on triangular fuzzy number was applied to assess the network security comprehensively and quantitatively. Computation results of example indicate that the fuzzy analytic hierarchy process is suitable for quantitative integration of qualitative judgment, and it provides an exploratory approach for computer network security assessment.

\section{Introduction}

Computer network security assessment is a basic work to determine the performance of network security and carry out the network security management, which involves a number of factors, such as organizational management, network technology, personnel psychology and social environment[1]. In recent years, with the rapid development of China's information technology, computer network security issues have become increasingly prominent. Although scholars have from different sides used different methods to find effective approaches to network security assessment, there are many factors difficult to quantify in the network security. So far, there is no more mature network security quantitative evaluation methods. Based on the factors affecting cybersecurity awareness, this paper established a complete set of computer network security evaluation system, and built a computer network security evaluation model based on triangular fuzzy numbers on the basis of the use of fuzzy analytic hierarchy process (FAHP). The example verifies its effective and feasible [2-3].

\section{Fuzzy analytic hierarchy process}

\section{The overview of FAHP.}

The basic idea of FAHP is that, in pairwise comparisons between factors, use triangular fuzzy number to instead of the traditional AHP 1-9 scale method to show the results of the comparison, get fuzzy judgment matrix composed by a triangular fuzzy number, which can blur the environment by using the AHP.

\section{Triangular fuzzy number.}

The triangular fuzzy number $\tilde{a}_{i j}$ is defined as:

$$
\tilde{a}_{i j}=\left(L_{i j}, M_{i j}, U_{i j}\right)
$$

Where $L_{i j} \leq M_{i j} \leq U_{i j}$, and $L_{i j}, M_{i j}, U_{i j}$ respectively represent the lower bound, median and upper bound of $\tilde{a}_{i j}$.

In the application of FAHP, the comparative judgment matrix obtained from 1-9 scale method 
can be regarded as triangular fuzzy number, in which:

$$
\begin{aligned}
& L_{i j}=\min \left(a_{i j k}\right) \\
& M_{i j}=\sqrt[n]{\prod_{k=1}^{n} a_{i j k}} \\
& U_{i j}=\max \left(a_{i j k}\right)
\end{aligned}
$$

\section{The steps of FAHP.}

(1) Establish the hierarchy structure model

At first, the problem needs to be divided in to different constituent elements according to the feature of the problem and the overall objective to be achieved. Then, in accordance with the relationship affiliation between factors, combine these factors with different levels and form a multi-layered structure model. Under this model, the level can be divided into three categories: the target layer, criterion layer and scheme layer.

(2) Establish fuzzy judgment matrix

Through using the pairwise comparison, the network security experts determine the important between each factor corresponding to the upper layer. Then, put the judgment in the Eq. (1) to be present with triangular fuzzy number, namely establishing the fuzzy judgment matrix:

$$
\tilde{A}=\left[\tilde{a}_{i j}\right]=\left[\begin{array}{cccc}
1 & \tilde{a}_{12} & \cdots & \tilde{a}_{1 n} \\
\tilde{a}_{21} & 1 & \cdots & \tilde{a}_{2 n} \\
\vdots & \vdots & \ddots & \vdots \\
\tilde{a}_{n 1} & \tilde{a}_{n 2} & \cdots & 1
\end{array}\right]
$$

Where, the triangular fuzzy number $\tilde{a}_{i j}$ represents the relative importance of $A_{j}$ from $A_{i}$.

(3) Defuzzification

The purpose of defuzzification is transferring the fuzzy judgment matrix into non-fuzzy judgment matrix. Then, under the non-blurred environment, the AHP method is used directly. This paper applies the following method to defuzzify $\tilde{a}_{i j}$ :

$$
\begin{aligned}
& \left(a_{i j}^{\alpha}\right)^{\lambda}=\left[\lambda \cdot L_{i j}^{\alpha}+(1-\lambda) \cdot U_{i j}^{\alpha}\right] \\
& \left(a_{i j}^{\alpha}\right)^{\lambda}=1 /\left(a_{j i}^{\alpha}\right)^{\lambda}
\end{aligned}
$$

Where

$$
\begin{aligned}
& L_{i j}^{\alpha}=\left(M_{i j}-L_{i j}\right) \cdot \alpha+L_{i j} \\
& U_{i j}^{\alpha}=U_{i j}-\left(U_{i j}-M_{i j}\right) \cdot \alpha
\end{aligned}
$$

In which, $0 \leq \alpha \leq 1,0 \leq \lambda \leq 1, i<j ; \quad \alpha$ is defined as the preference coefficient of decision-makers; $\lambda$ is defined as the risk tolerance of decision-makers; $L_{i j}^{\alpha}$ and $U_{i j}^{\alpha}$ respectively is defined as left value and right value of the cut set. The judgment matrix after defuzzification is as follows: 


$$
\left(A^{\alpha}\right)^{\lambda}=\left[\left(a_{i j}^{\alpha}\right)^{\lambda}\right]=\left[\begin{array}{cccc}
1 & \left(a_{12}^{\alpha}\right)^{\lambda} & \ldots & \left(a_{1 n}^{\alpha}\right)^{\lambda} \\
\left(a_{21}^{\alpha}\right)^{\lambda} & 1 & \ldots & \left(a_{2 n}^{\alpha}\right)^{\lambda} \\
\vdots & \vdots & \ddots & \vdots \\
\left(a_{n 1}^{\alpha}\right)^{\lambda} & \left(a_{n 2}^{\alpha}\right)^{\lambda} & \ldots & 1
\end{array}\right]
$$

(4) Single layer sorting

The feature vector corresponding to the maximum eigenvalue $\lambda_{\max }$ of the judgment matrix after defuzzification $\left(A^{\alpha}\right)^{\lambda}$ is $W$. Through the normalization, the feature vector is the weight sorting of the relative importance of the same layer to the previous layer. The eigenvalue $\lambda_{\max }$ and feature vector $W$ can be calculated by Eq. (11).

$$
\left\lfloor\left(A^{\alpha}\right)^{\lambda}-\bar{\lambda}\right\rfloor \cdot W=0
$$

Where the maximum eigenvalue $\lambda_{\max }$ equals to $\max (\bar{\lambda})$.

(5) Total layer sorting

The purpose of total layer sorting is to calculate the weight sorting from the bottom scheme layer to the target layer. The calculation of the weight applies the top-down approach, and the results of single layer sort is made up. The total weight of the target layer of the programs can be obtained according to Eq. (14).

$$
W_{l}=\sum_{i, j} w_{i} w_{i j} w_{i j l}
$$

Where, $W_{l}$ represents the weight of the $l$ th scheme corresponding to target layer $O$; $w_{i}$ represents the weight of the criterion $C_{i}$ corresponding to target layer $O ; w_{i j}$ represents the weight of the sub-criterion $C_{i j}$ corresponding to the criterion $C_{i} ; w_{i j l}$ represents the weight of the $l$ th scheme corresponding to the sub-criterion $C_{i j}$.

\section{The application of FAHP in computer network security assessment}

Five experts are invited to make a comprehensive assessment for the computer network security situation of three enterprises: A, B and C.

Hierarchy structure model of network security assessment.

Comprehensively considering the management and technology factor of computer network security, this paper builds the following hierarchy structure model, which is shown in Fig. 1.

The layers in Fig. 1 are respectively target layer $(\mathrm{O})$, criterion layer $\left(\mathrm{C}_{1}\right.$-Management security, $\mathrm{C}_{2}$-Physical security, $\mathrm{C}_{3}$-Logical security), sub-criterion layer $\left(\mathrm{C}_{11}\right.$-Security organization and personnel, $\mathrm{C}_{12}$-Security management system, $\mathrm{C}_{13}$-Security training system, $\mathrm{C}_{14}$-Emergency response mechanism, $\mathrm{C}_{21}$-Room and safety equipment, $\mathrm{C}_{22}$-line security, $\mathrm{C}_{23}$-power system security, $\mathrm{C}_{24}$-Anti-electromagnetic leak measures, $\mathrm{C}_{31}$-Data backup and recovery, $\mathrm{C}_{32}$-Encryption, $\mathrm{C}_{33}$-Access control, $\mathrm{C}_{34}$-Security audit, $\mathrm{C}_{35}$-Virus precautions, $\mathrm{C}_{36}$-Intrusion prevention measures) and scheme layer (A, B, C). 


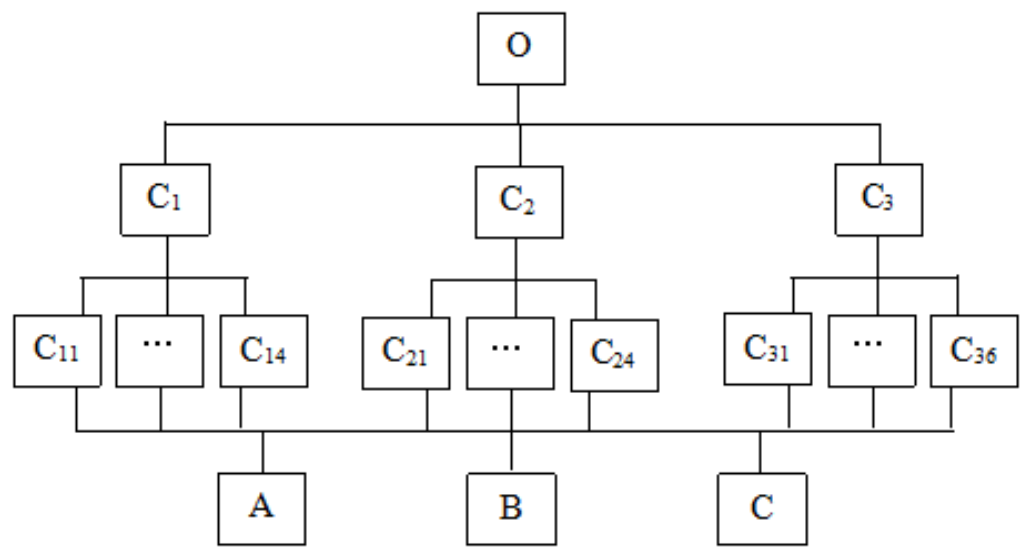

Fig. 1 The hierarchy structure model of computer network security assessment

\section{Establish fuzzy judgment matrix.}

In the process of assessment, the experts should make the pairwise comparison to each factors in the hierarchy structure model. According to experts on the relative importance of each factor between the judge, and the aforementioned method of fuzzy judgment matrix structure, the different layers' fuzzy judgment matrix is established. Table. 1 shows the fuzzy judgment matrix of criterion layer corresponding to target layer.

Table. 1 The fuzzy judgment matrix of criterion layer corresponding to target layer.

\begin{tabular}{cccc}
\hline $\mathrm{O}$ & $\mathrm{C}_{1}$ & $\mathrm{C}_{2}$ & $\mathrm{C}_{3}$ \\
\hline $\mathrm{C}_{1}$ & $(1,1,1)$ & $(0.33,0.70,1)$ & $(0.2,0.27,0.33)$ \\
$\mathrm{C}_{2}$ & $(1,1.43,3)$ & $(1,1,1)$ & $(0.33,0.56,1)$ \\
$\mathrm{C}_{3}$ & $(3,3.68,5)$ & $(1,1.78,3)$ & $(1,1,1)$ \\
\hline
\end{tabular}

Similarly, the fuzzy judgment matrix of sub-criterion layer corresponding to criterion layer can be established. Due to the space limitation, only the sub-criterion layer corresponding to $\mathrm{C}_{1}$ is listed here, which is shown in Table. 2.

Table. 2 The the fuzzy judgment matrix of sub-criterion layer corresponding to $\mathrm{C}_{1}$

\begin{tabular}{ccccc}
\hline $\mathrm{C}_{1}$ & $\mathrm{C}_{11}$ & $\mathrm{C}_{12}$ & $\mathrm{C}_{13}$ & $\mathrm{C}_{14}$ \\
\hline $\mathrm{C}_{11}$ & $(1,1,1)$ & $(1,1.43,3)$ & $(1,1.64,3)$ & $(1,1.43,3)$ \\
$\mathrm{C}_{12}$ & $(0.33,0.70,1)$ & $(1,1,1)$ & $(1,1.15,2)$ & $(1,1.32,2)$ \\
$\mathrm{C}_{13}$ & $(0.33,0.61,1)$ & $(0.5,0.87,1)$ & $(1,1,1)$ & $(0.5,0.76,1)$ \\
$\mathrm{C}_{14}$ & $(0.33,0.70,1)$ & $(0.5,0.76,1)$ & $(1,1.32,2)$ & $(1,1,1)$ \\
\hline
\end{tabular}

The fuzzy judgment matrix of scheme layer corresponding to sub-criterion layer is shown in Table. 3.

Table. 3 The fuzzy judgment matrix of scheme layer corresponding to sub-criterion layer

\begin{tabular}{ccccc}
\hline & & $\mathrm{A}$ & $\mathrm{B}$ & $\mathrm{C}$ \\
\hline \multirow{4}{*}{$\mathrm{C} 11$} & $\mathrm{~A}$ & $(1,1,1)$ & $(1,1.64,3)$ & $(0.33,0.74,2)$ \\
& $\mathrm{B}$ & $(0.33,0.61,1)$ & $(1,1,1)$ & $(0.33,0.61,1)$ \\
& $\mathrm{C}$ & $(0.5,1.35,3)$ & $(1,1.64,3)$ & $(1,1,1)$ \\
\hline \multirow{3}{*}{$\mathrm{C} 12$} & $\mathrm{~A}$ & $(1,1,1)$ & $(0.33,0.56,1)$ & $(1,1.43,3)$ \\
& $\mathrm{B}$ & $(1,1.78,3)$ & $(1,1,1)$ & $(1,2.35,4)$ \\
& $\mathrm{C}$ & $(0.33,0.70,1)$ & $(0.25,0.43,1)$ & $(1,1,1)$ \\
\hline$\ldots$ & & $\cdots$ & $\cdots$ & $\cdots$ \\
\hline \multirow{2}{*}{ C36 } & A & $(1,1,1)$ & $(0.33,0.56,1)$ & $(0.33,0.53,1)$ \\
& $\mathrm{B}$ & $(1,1.78,3)$ & $(1,1,1)$ & $(0.5,0.87,2)$ \\
& $\mathrm{C}$ & $(1,1.89,3)$ & $(0.5,1.15,2)$ & $(1,1,1)$ \\
\hline
\end{tabular}




\section{Defuzzification and single-layer sorting.}

According to Eq. (6) and Eq. (7), make defuzzification to the above fuzzy judgment matrix. Applying the single-layer root method, we can calculate the weight vector of judgment matrix after defuzzification, and the results are shown in Table. 4 to Table. 6.

Table. 4 The defuzzification judgment matrix of criterion layer corresponding to target layer

\begin{tabular}{|c|c|c|c|c|}
\hline $\mathrm{O}$ & $\mathrm{C}_{1}$ & $\mathrm{C}_{2}$ & $\mathrm{C}_{3}$ & Weight \\
\hline $\mathrm{C}_{1}$ & 1 & 0.68 & 0.27 & 0.169 \\
\hline $\mathrm{C}_{2}$ & 1.47 & 1 & 0.61 & 0.288 \\
\hline $\mathrm{C}_{3}$ & 3.72 & 1.83 & 1 & 0.543 \\
\hline
\end{tabular}

Table. 5 The defuzzification judgment matrix of sub-criterion layer corresponding to criterion layer

\begin{tabular}{|c|c|c|c|c|c|c|c|}
\hline $\mathrm{C}_{1}$ & \multicolumn{2}{|c|}{$\mathrm{C}_{11}$} & $\mathrm{C}_{12}$ & $\mathrm{C}_{13}$ & \multicolumn{2}{|c|}{$\mathrm{C}_{14}$} & Weight \\
\hline $\mathrm{C}_{11}$ & \multicolumn{2}{|c|}{1} & 1.72 & 1.82 & \multicolumn{2}{|c|}{1.72} & 0.367 \\
\hline $\mathrm{C}_{12}$ & \multicolumn{2}{|c|}{0.58} & 1 & 1.32 & \multicolumn{2}{|c|}{1.41} & 0.246 \\
\hline $\mathrm{C}_{13}$ & \multicolumn{2}{|c|}{0.55} & 0.76 & 1 & \multicolumn{2}{|c|}{0.75} & 0.180 \\
\hline $\mathrm{C}_{14}$ & \multicolumn{2}{|c|}{0.58} & 0.71 & 1.33 & \multicolumn{2}{|c|}{1} & 0.207 \\
\hline $\mathrm{C}_{2}$ & \multicolumn{2}{|c|}{$\mathrm{C}_{21}$} & $\mathrm{C}_{22}$ & $\mathrm{C}_{23}$ & \multicolumn{2}{|c|}{$\mathrm{C}_{24}$} & Weight \\
\hline $\mathrm{C}_{21}$ & \multicolumn{2}{|c|}{1} & 1.20 & 1.13 & \multicolumn{2}{|c|}{1.82} & 0.306 \\
\hline $\mathrm{C}_{22}$ & \multicolumn{2}{|c|}{0.83} & 1 & 0.81 & \multicolumn{2}{|c|}{1.41} & 0.242 \\
\hline $\mathrm{C}_{23}$ & \multicolumn{2}{|c|}{0.89} & 1.23 & 1 & \multicolumn{2}{|c|}{1.51} & 0.277 \\
\hline $\mathrm{C}_{24}$ & \multicolumn{2}{|c|}{0.55} & 0.71 & 0.66 & \multicolumn{2}{|c|}{1} & 0.174 \\
\hline $\mathrm{C}_{3}$ & $\mathrm{C}_{31}$ & $\mathrm{C}_{32}$ & $\mathrm{C}_{33}$ & $\mathrm{C}_{34}$ & $\mathrm{C}_{35}$ & $\mathrm{C}_{36}$ & Weight \\
\hline $\mathrm{C}_{31}$ & 1 & 1.89 & 1.82 & 2.11 & 1.13 & 0.75 & 0.212 \\
\hline $\mathrm{C}_{32}$ & 0.53 & 1 & 1.13 & 1.72 & 0.60 & 0.40 & 0.124 \\
\hline $\mathrm{C}_{33}$ & 0.55 & 0.89 & 1 & 1.82 & 0.68 & 0.61 & 0.133 \\
\hline $\mathrm{C}_{34}$ & 0.47 & 0.58 & 0.55 & 1 & 0.54 & 0.39 & 0.088 \\
\hline $\mathrm{C}_{35}$ & 0.89 & 1.67 & 1.47 & 1.85 & 1 & 0.75 & 0.188 \\
\hline $\mathrm{C}_{36}$ & 1.33 & 2.47 & 1.63 & 2.57 & 1.33 & 1 & 0.254 \\
\hline
\end{tabular}

Table. 6 The defuzzification judgment matrix of scheme layer corresponding to sub-criterion layer

\begin{tabular}{ccccc}
\hline $\mathrm{C}_{11}$ & $\mathrm{~A}$ & $\mathrm{~B}$ & $\mathrm{C}$ & Weight \\
\hline $\mathrm{A}$ & 1 & 1.82 & 0.95 & 0.389 \\
$\mathrm{~B}$ & 0.55 & 1 & 0.64 & 0.228 \\
$\mathrm{C}$ & 1.05 & 1.57 & 1 & 0.382 \\
\hline $\mathrm{C}_{12}$ & $\mathrm{~A}$ & $\mathrm{~B}$ & $\mathrm{C}$ & Weight \\
\hline $\mathrm{A}$ & 1 & 0.61 & 1.72 & 0.316 \\
$\mathrm{~B}$ & 1.63 & 1 & 2.43 & 0.491 \\
$\mathrm{C}$ & 0.68 & 0.41 & 1 & 1.93 \\
$\cdots$ & $\cdots$ & $\cdots$ & $\cdots$ & $\cdots$ \\
\hline $\mathrm{C}_{36}$ & $\mathrm{~A}$ & $\mathrm{~B}$ & $\mathrm{C}$ & Weight \\
\hline $\mathrm{A}$ & 1 & 0.61 & 0.60 & 0.232 \\
$\mathrm{~B}$ & 1.63 & 1 & 1.06 & 0.390 \\
$\mathrm{C}$ & 1.67 & 0.94 & 1 & 0.378 \\
\hline
\end{tabular}

Total layer sorting.

Put the result of single layer sorting in Eq. (14), in order to calculate the weight value of 
computer network security situation of these three enterprises. After comprehensive assessment, the weight value of computer network security assessment are respectively 0.316,0.347 and 0.337, which indicates that the computer network security situation of these three companies are similar, and the situation of the second company is the best.

\section{Conclusions}

Computer network security is related to complex factors, such as management and technology. And its comprehensive quantitative assessment requires the use of scientific and efficient way. This paper introduced FAHP method which is in line with the features and requirements of computer network security. Application-related examples shows that, FAHP method is an exploratory approach to achieve computer network security quantitative assessment.

\section{References}

[1] Fei Jun, Yu Lihua. Computer network security evaluation with FAHP. Computer Application and Software, Volume 28, Issue 10 (2011), P. 120-123.

[2] Liu Qiuhong, Xu Guangfei. Role exploring of neural network in computer network security assessment. Coal Technology, Volume 32, Issue 3 (2013), P. 270-272.

[3] Huang Weili, Li Rui, Guan Rui. Assessment system for the security of the computer network information. Journal of Heibei Institute of Architectural Science and Technology, Volume 22, Issue 2 (2005), P. 47-50. 